\title{
Preface and Acknowledgments
}

I have been studying fishes most of my professional life, starting from when I was an undergraduate student. I find them fascinating to study and just love to watch them. Other people who are not biologists also seem to be interested in fishes for many reasons: they like to go fishing, look at fishes in aquariums or go scuba diving, or they may like to eat them. They are curious about the lives of fishes. This book attempts to answer questions they may have about these fascinating creatures that live in such a very different world than we do. I have tried to provide basic biological information at a level understandable by the general public, while including lots of up-to-date scientific information about basic biology, where fishes live, their amazing behaviors, the dangers they face, their ecology, and the myriads of ways they reproduce. The book is written in a non-technical style with a question-and-answer format that should be easy to read. Quite a bit of space is devoted to the ongoing crisis in the sustainability of fishing and, indeed, the continued existence of many fish species, so that readers may become better informed about these vital issues. I hope that the book will convey my enthusiasm about the fascinating lives of fishes and my concern over their future. I hope it will stimulate readers to learn more and contribute to the conservation of these wonderful creatures.

I want to thank Carol Butler, coauthor of my previous book, Salt Marshes: A Natural and Unnatural History. We developed the idea 
for this book together, and she was initially supposed to be the co-author and did some writing until bowing out. My husband, Peddrick Weis, has been a research colleague for decades and a strong supporter throughout the development of this book. Pete also is responsible for taking some of the photographs here, as well as preparing the photos taken by others. I am grateful to those who contributed their photos.

As a seven-year-old, summering on Shelter Island, New York, I discovered a fascination with marine life that is still with me. I am grateful that Dr. Evelyn Shaw took me on as an undergraduate for summer research at Woods Hole, where I did my first bit of fish research. The following year, the Marine Biological Laboratory's course entitled Marine Ecology, taught by Eugene Odum, Howard Sanders, and Laurence Slobodkin, among others, expanded my knowledge of coastal ecology, including fishes. My professors William MacFarland, Alfred Perlmutter, and James Atz greatly expanded my interest in and knowledge about fishes.

Many graduate students who worked in my lab have provided stimulation and interesting new information in fish biology. Thank you all for your enthusiasm, good work, and good company. Research Associate Dr. Terry Glover provided invaluable insights into animal behavior and statistics. I thank Emily Miner for drawing my attention to the blobfish.

I am grateful to the National Science Foundation, National Oceanic and Atmospheric Administration, Environmental Protection Agency, U.S. Geological Survey, New Jersey Sea Grant Program, New Jersey Department of Environmental Protection, and the Meadowlands Environmental Research Institute for supporting our research.

I appreciate the hard work of all the environmental groups that are working to protect fishes and their habitats, wherever they are.

I am grateful to Cile Downs and Vay David for looking over the chapters and to my editor Doreen Valentine and agent Deirdre Mullane for all their help on this project. 
Do Fish Sleep? 
